\title{
Microstructure Evolution during Cold-Deformation and Aging Response after Annealing of TB8 Titanium Alloy
}

\author{
Xu Tiewei ${ }^{1,2}$, Li Jinshan', Zhang Fengshou ${ }^{1,2}$, Wang Feiyun ${ }^{2}$, Liu Xianghong ${ }^{1,2}$, \\ Feng Yong ${ }^{1,2}$
}

${ }^{1}$ Northwestern Polytechnical University, Xi'an 710072, China; ${ }^{2}$ Western Superconducting Technology Co., LTD, Xi'an 710018, China

\begin{abstract}
The microstructure evolution of titanium alloy is decided by deformation degree in cold-deformation process, and substructures resulting from different cold deformations significantly influence phase transformation behavior in isothermal aging treatment. The microstructure evolution in cold-deformation and the followed aging behavior of TB8 alloy were investigated by X-ray diffraction (XRD), Vickers hardness (HV), field emission scanning electron microscope (FESEM) and differential scanning calorimeter (DSC). Results show that the high value of FWHM results from the combination of the grain distortion and dislocations, and the enhancement of the distortion and dislocations is accompanied by increasing of HV value. The phase transformation of the present investigation exhibits the effect of cold-deformation on transformation behavior of $\alpha$ phase precipitation in the $\beta$ matrix. It is suggested that there is a distinctive behavior in the aging transformation of cold-deformed titanium alloy.
\end{abstract}

Key words: phase transformation; cold-deformation; titanium alloy; aging response

Titanium alloys are well known as aerial materials due to their excellent strength-to-weight ratio and corrosion resistance $e^{[1,2]}$. Titanium alloys are usually classified into three types according to the percentage composition of alloying elements, and the main phases in titanium alloys are $\alpha$ phase with hexagonal close packed (hcp) structure and $\beta$ phase with body centered cubic (bcc) structure ${ }^{[3,4]}$. Molybdenum, vanadium and niobium are representatives of beta stabilizer elements of titanium alloys ${ }^{[5]}$. The substructure evolution and phase transformation of Ti-Al-Mo, Ti-Al-Nb, and Ti-Al-V ternary titanium alloys have been investigated since $1960 \mathrm{~s}^{[4-6]}$, but little detailed study has been conducted on the Ti-Al-Mo-Nb quaternary alloys as invented later. Nominal composition of TB8 titanium alloy is Ti-15Mo-3Al- $2.7 \mathrm{Nb}-0.2 \mathrm{Si}$, which is a typical Ti-Al-Mo-Nb quaternary alloy since 1980s. The strength of the alloy is more than $1300 \mathrm{MPa}$, which was treated in solution plus aging condition. The alloy has excellent cold deformation performances, so was used for foils for the part of aero-engine. In recent years, TB8 alloy is used for manufacturing aircraft fasteners instead of steel or TC4 alloy.
Titanium alloys are easy to generate a microstructure evolution or a phase transformation in the cold rolling process. Sun found that stress or strain induced $\alpha^{\prime \prime}$ martensite with less stable $\beta$ and formed $\{332\}<113>$ twin with more stable $\beta$ when Ti-Mo titanium alloys were studied ${ }^{[6,7]}$. Mantani illustrated phase transformation of $\alpha^{\prime \prime}$ martensite when isothermal aging treatment of Ti-Nb alloy was studied ${ }^{[5]}$. This work is aimed to predict the TB8 alloy phase transformation associated with different cold-deformations and the microstructure evolution behavior in continuing isothermal aging treatment. The purpose of the present paper is to show two issues: (1) to investigate the microstructure evolution behavior and regulation of TB8 alloy in different cold-deformation conditions; (2) to study the effect of cold-deformation through analyzing the essence of phase transformation during the aging treatment.

\section{Experiment}

TB8 titanium alloy used in the present investigation was manufactured by WST (Western Superconducting Technology 
Co., LTD). It was melted three times by vacuum arc remelting (VAR) with chemical composition shown in Table 1. The TB8 bars with $14 \mathrm{~mm}$ in diameter were solid solutioned at $870{ }^{\circ} \mathrm{C}$ for $1 \mathrm{~h}$, then water quenched, followed by cold rolling at different deformation degrees of $2 \%, 20 \%, 36 \%, 40 \%$ and $50 \%$, respectively, and finally aged at $500{ }^{\circ} \mathrm{C}$ for 8 h. Fig. 1 shows the schematic of the experimental process. The samples for optical micrographs were prepared by the etchant of $\mathrm{HF}$ $(10 \%$ vol $)+\mathrm{HNO}_{3}(10 \% \mathrm{vol})+$ water $(80 \% \mathrm{vol})$. DSC was conducted at a constant heating rate of $30{ }^{\circ} \mathrm{C} / \mathrm{min}$ to $500{ }^{\circ} \mathrm{C}$ holding for $8 \mathrm{~h}$ in an $\mathrm{Ar}$ atmosphere to predict the phase transformation behavior. The load applied in the Vickers hardness test was $98 \mathrm{~N}$ and the holding time was $30 \mathrm{~s}$. XRD using $\mathrm{CuK} \alpha$ was performed at $40 \mathrm{kV}, 40 \mathrm{~mA}$ to determine the difference of cold-deformed specimens. FESEM was performed at $5 \mathrm{kV}$ and second electron image (SEI) to observe precipitates of phase transformation alloy.

\section{Results and Discussion}

\subsection{Substructure evolution of the TB8 alloy after cold- deformation}

Optical micrographs of TB8 titanium alloy after different cold-deformation are presented in Fig.2. Fig.2a shows a longitudinal-section image of the alloy after cold-rolling at about $2 \%$ cross-section reduction. This micrograph shows a few sub-grains distributed in a few grains and most of the grains are nearly non-deformed when cold-rolling is conducted at a low deformation degree. This phenomenon was reported in steel and other titanium alloy studies, and the strain is implemented by transformation induced plasticity (TRIP) $^{[6,8]}$. After $20 \%$ deformation, a partial grain elongating zones become visible, and sub-grains appear in all of grains (Fig.2b). In the $40 \%$ deformed sample, sub-grains orientate along rolling direction, and a few deformation zones appear through the grain boundaries. Fig.2c suggests that the primary deformation causes dislocation slip. The micrograph of the $50 \%$ deformed sample reveals that the great stain is conducted in cold- deformation zones. Fig. $2 \mathrm{~d}$ shows that it is hard to find out complete grains in the $50 \%$ deformed sample.

Fig. 3 shows the hardness of TB 8 alloy vs deformation degree. Experimental results are in good agreement with the fit curve. It is obvious that the hardness of deformed TB8 alloy sample increases with the increase of deformation degree.

Table 1 Chemical composition of $\beta$-phase transformation temperature at $820{ }^{\circ} \mathrm{C}$ of $\mathrm{TB8}$ alloy (wt\%)

\begin{tabular}{rcccc}
\hline $\mathrm{Ti}$ & $\mathrm{Mo}$ & $\mathrm{Nb}$ & $\mathrm{Al}$ & $\mathrm{Si}$ \\
\hline Bal. & 14.97 & 2.83 & 3.01 & 0.19 \\
\hline
\end{tabular}

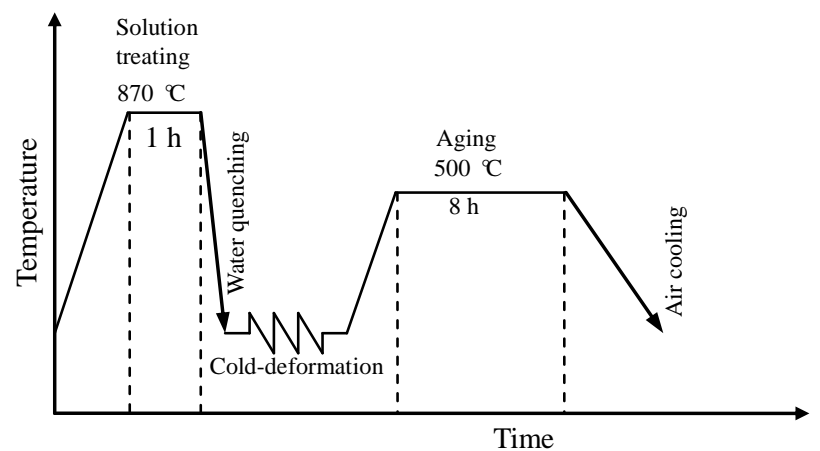

Fig.1 Schematic of the experimental processes

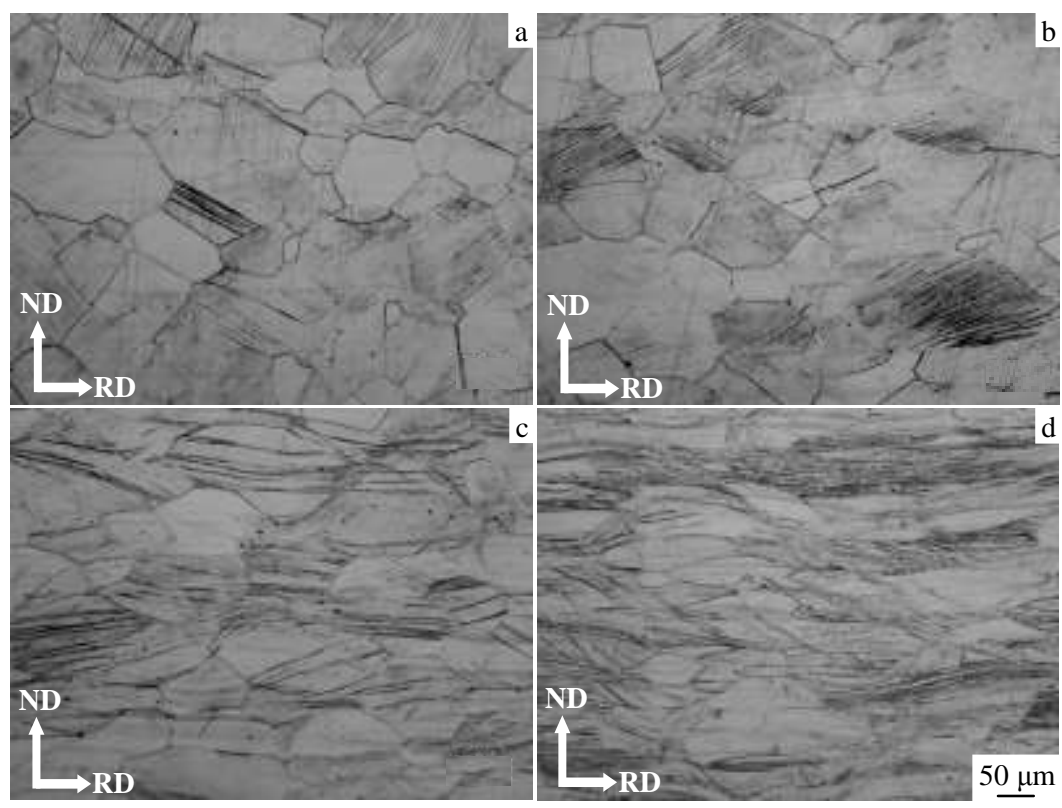

Fig.2 Optical micrographs of cold rolled samples after different cold deformations (cross-section reductions): (a) 2\%, (b) 20\%, (c) $40 \%$, and (d) $50 \%$ 


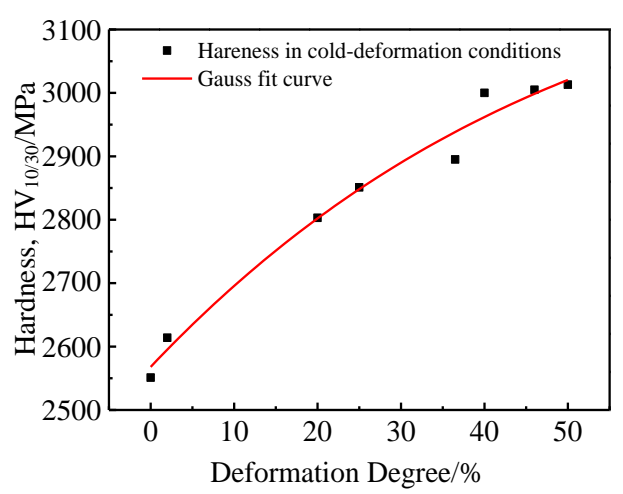

Fig.3 Hardness of TB8 alloy vs deformation degree

\subsection{XRD phase analysis of the TB8 alloy after cold-deformation}

Fig. 4 shows the XRD patterns of TB8 alloy solid solutioned after different cold-deformations. It is seen that TB8 alloy after solution treatment is comprised of single $\beta$ phase. Clear evidence of the sub-grain formation is seen after $20 \%$ cold deformation. In the same test condition, with further increase in the degree of cold deformation, a progressive increase in the width of (110) $\beta$ peak appears. The reason is that the sub-grains and dislocations are under-complete or the instrument of XRD test is under-precise when the test of $20 \%$ deformation is conducted. The (200) $\beta$ and (220) $\beta$ phase peaks are scarcely visible on XRD patterns of specimens with $50 \%, 40 \%, 36 \%$ and $20 \%$ deformation degrees. (200) and (220) $\beta$ phases decrease with the development of cold deformation. In other words, the orientation of the alloy rotates to $<011>$ directions in the cold rolling process.

Some amount of broadening of (110) $\beta$ is observed after $20 \%, 36 \%, 40 \%$ and $50 \%$ cold-deformations sequentially. XRD patterns of the broaden peaks are shown in Fig.4. The patterns indicate that the dislocation density increases with the exception of the sub-grains formation in the cold deformation process. In view of the dependence of sub-grains formed with dislocation development, it is expected that an external stress will aid the generation of dislocations and the formation

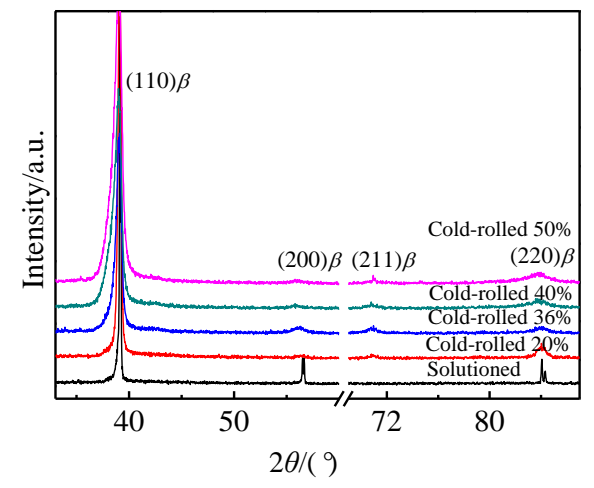

Fig.4 XRD patterns of TB8 alloy after different cold deformation of sub-grains. External stresses can also aid martensite nucleation if the external elastic strain components contribute to the deformation ${ }^{[9,10]}$. It should be expected that the increase in dislocation density by deformation will increase the width of (110) $\beta$ peak. The $\beta$ phase of plastically deforming has priority over forming sub-grains in the cold deformation process, but excess plastically deforming impedes the further transformation of martensite ${ }^{[10]}$.

The FWHM (full width half maximum) of the deformation alloy is often applied to evaluate the lattice tilt due to distortion or dislocations. The deformation of the grain, which is induced by sub-grain formation or dislocation slip, is less able to directly measure, so the FWHM values are used to attribute the deformation $^{[11]}$. Fig.5 shows FWHM values of TB8 alloy after different cold-deformations, and it was calculated from (110) $\beta$ peak using MDI-JADE software. It is clearly seen that the FWHM values increase with the increase of the cold deformation degree. Nonlinear variation of FWHM value appears while deformation degree excesses $36 \%$. It is suggested that the primary factor of plastic deformation has changed from sub-grain formation to dislocation slip.

\subsection{DSC analysis of the cold rolled TB8 alloy after aging treatment}

In order to confirm the definite occurrence of a phase transformation in $500{ }^{\circ} \mathrm{C}$ aging treatment process, an isothermal differential scanning calorimeter (DSC) analysis was conducted to TB8 alloy after cold deformation. The resulting DSC thermogram is shown in Fig.6. Thermograms of deformed specimens were recorded to investigate the thermal behavior and phase transition property ${ }^{[12]}$. It is evident from this figure that clear inflections are observed in $20 \%$, $36 \%, 50 \%$ deformed specimens at about $100 \mathrm{~s}$, but no similar inflection appears on the $870{ }^{\circ} \mathrm{C}$ solutioned specimen. This result provides a support to the incidence of possible phase transformation in the deformed specimens. It is considered that $\alpha$ precipitation at dislocation sites has occurred, since DSC thermogram has an exothermic peak in this stage. There is an endothermic peak at about $360 \mathrm{~s}$ in all of specimens. It is considered that the transformation of $\beta$ phase to $\alpha$ phase has occurred. Thermographs in Fig.6 reveal another result that all

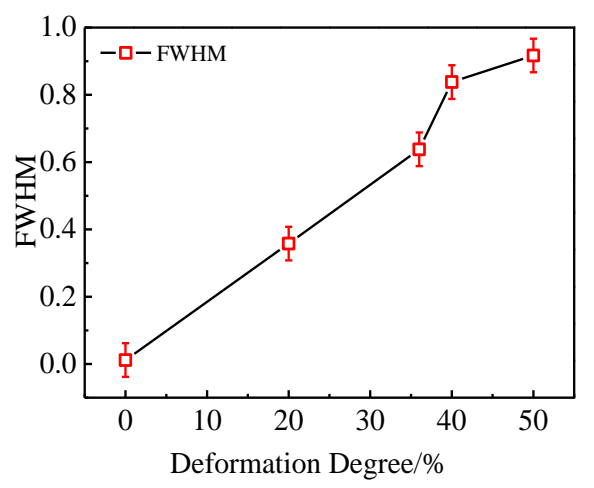

Fig.5 FWHM value of TB8 alloy vs cold deformation degree 


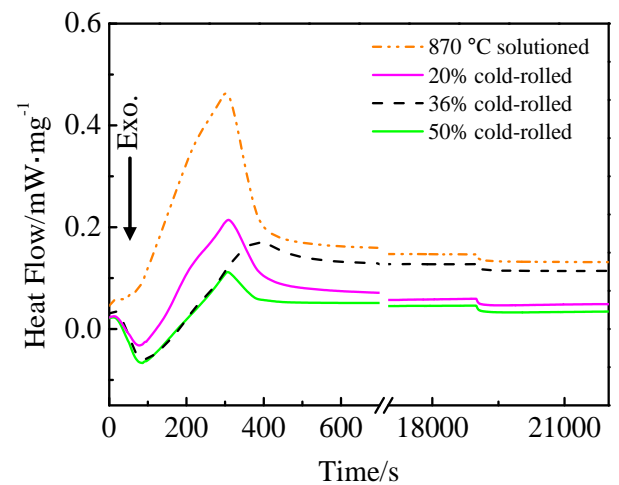

Fig.6 DSC thermograms of differently deformed specimens in $500{ }^{\circ} \mathrm{C}$ aging treatment process

of transformations are finished at about $20000 \mathrm{~s}(5.5 \mathrm{~h})$ whether specimens are cold-rolled or not.

\subsection{Variation of aged microstructure with deformation degrees}

Fig.7 shows the micrographs of TB8 alloy treated at $500{ }^{\circ} \mathrm{C}$ for $8 \mathrm{~h}$ after $2 \%, 20 \%, 40 \%$ and $50 \%$ deformation. The microstructures of the specimens deformed by cold rolling followed by isothermal aging exhibit the relationship of cold deformation and phase transformation ${ }^{[13,14]}$. The precipitates produced in aging at $500{ }^{\circ} \mathrm{C}$ present obvious morphological features after 2\%, 20\%, 40\% and 50\% deformations. Fig.7a and $7 \mathrm{~b}$ show the morphologies of $\alpha$ precipitates transformation from $\beta$ phase after $2 \%$ deformation. The zone between two white lines is considered as $\alpha$ phase zone where the transformation of $\beta$ phase will occur, and $\alpha$ phase (the arrow point zone) is finer than that from $\beta$ matrix. Fig.7c and $7 \mathrm{~d}$ show similar status after $20 \%$ deformation, except that the distance of finer $\alpha$ zone and $\beta \rightarrow \alpha$ zone is shorter than that after $2 \%$ deformation. The precipitates of the specimen after $40 \%$ deformation have smaller size as shown in Fig.7e and $7 \mathrm{f}$, and exhibit a little zone which has experienced less deformation with larger size precipitates. Fig. $7 \mathrm{~g} \sim 7 \mathrm{i}$ show the morphology of $\alpha$ phase transformed from $\beta$ phase after $50 \%$ deformation. The distance of two deformed grain boundaries (GB) is about $3 \mu \mathrm{m}$ as shown in Fig.7h, and there are all small size precipitates between two grain boundaries. It is considered that severe cold-deformation generates lots of dislocations which provide the nucleation sites of precipitates and impede $\alpha$ phase growth. Fig.7i shows the morphology of

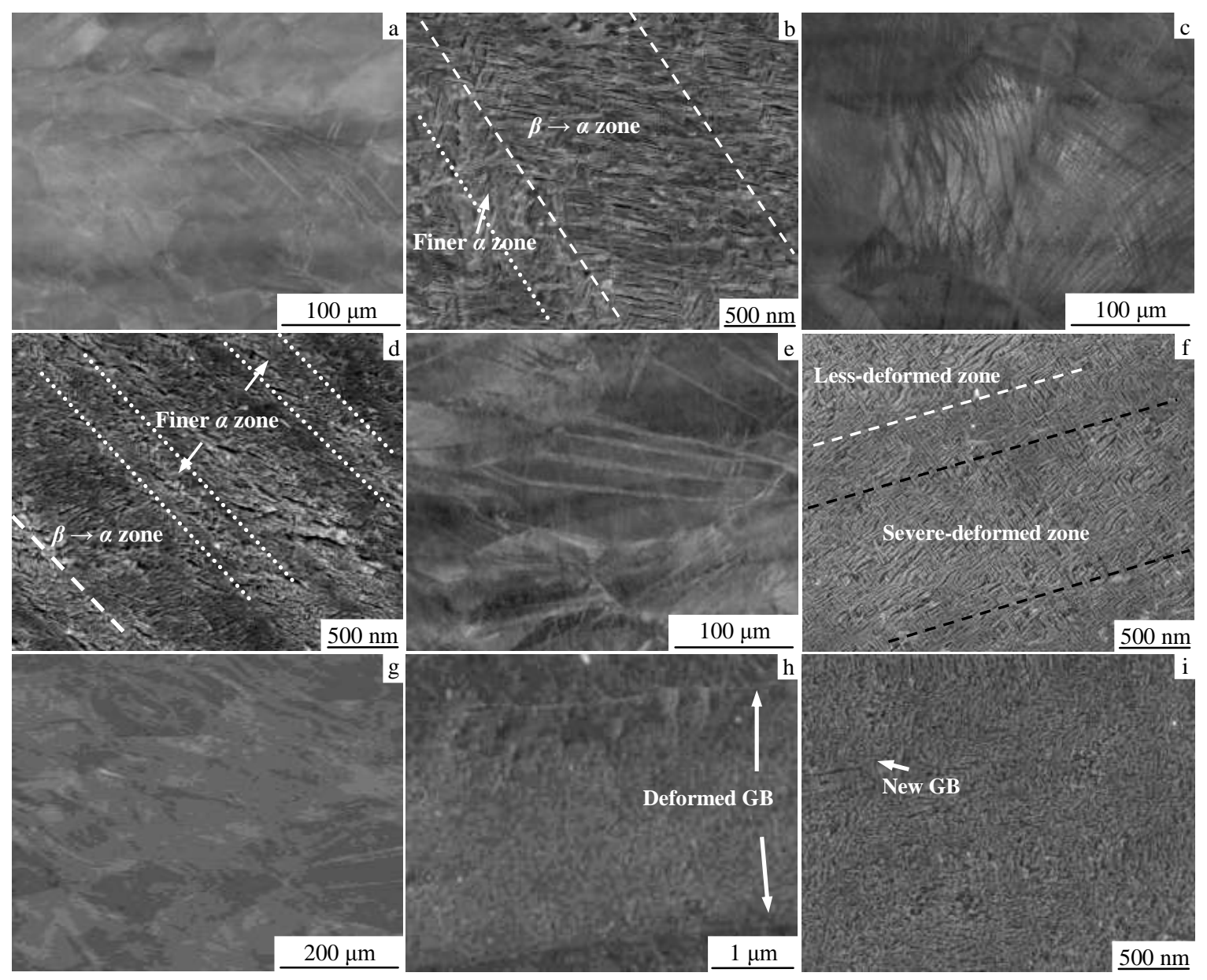

Fig.7 Microstructures of the alloy aged at $500{ }^{\circ} \mathrm{C}$ for $8 \mathrm{~h}$ after different deformations: (a, b) $2 \%$, (c, d) $20 \%$, (e, f) $40 \%$, (g i) 50\%; (a, c, e, g) optical micrographs and (b, d, f, h, i) FESEM micrographs 
the new grain boundaries in a magnified micrograph. XRD analysis also shows that there are more dislocations after $50 \%$ deformation.

\subsection{Performance of the cold rolled TB8 alloy after aging treatment}

The results of hardness measurements made to the specimens aged at $500{ }^{\circ} \mathrm{C}$ for $8 \mathrm{~h}$ after different cold-deformations are displayed in Table 2. Very little variation of the hardnesses for the specimens with different deformation degrees is observed clearly. In those specimens there exists completed $\alpha$-phase transformation, and the hardness is decided by the composition of $\alpha$ precipitates even if those endure different cold-deformations. The constant hardness behavior is due to the similar volume fraction of $\alpha$ precipitates transformed from $\beta$ phase during aging treatment process.

Fig. 8 shows the variation of strength and ductility of the alloy treated at $500{ }^{\circ} \mathrm{C}$ for $8 \mathrm{~h}$ after different cold-deformations. The strength increases with increasing of cold-deformation degree and the ductility changes in an opposite way. The highest ultimate strength of $1795 \mathrm{MPa}$ is achieved when the sample is treated at $500{ }^{\circ} \mathrm{C}$ for $8 \mathrm{~h}$ after $50 \%$ deformation, but its elongation is nearly approximate at zero. There is a good combination of strength and ductility for the $20 \%$ deformed sample, and it has $6.5 \%$ elongation with a reasonable ultimate strength of $1507 \mathrm{MPa}$.

Tensile properties of the deformed alloy in aging condition

Table 2 Hardness of TB8 alloy aged at $500{ }^{\circ} \mathrm{C}$ for $8 \mathrm{~h}$ after different mounts of cold-deformation

\begin{tabular}{ccc}
\hline Cold-deformation degree/\% & $\begin{array}{c}\text { Hardness, } \\
\mathrm{HV}_{10 / 30} / \mathrm{MPa}\end{array}$ & Tolerance \\
\hline 2 & 4294 & \pm 100 \\
20 & 4296 & \pm 120 \\
25 & 4229 & \pm 100 \\
36.5 & 4138 & \pm 80 \\
40 & 4177 & \pm 90 \\
46 & 4240 & \pm 100 \\
\hline
\end{tabular}

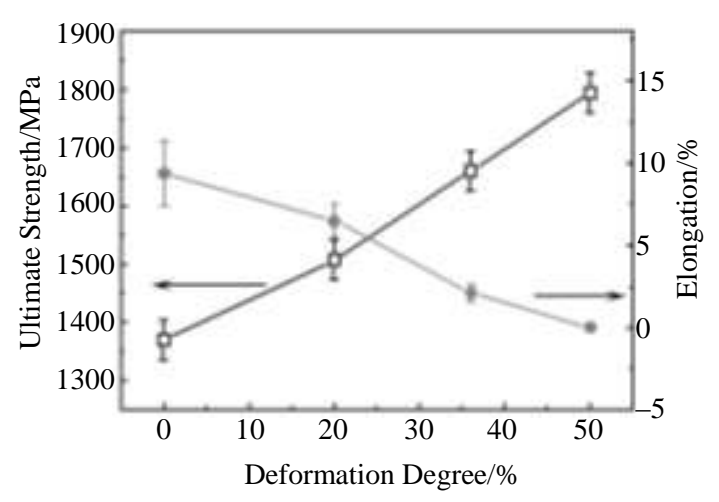

Fig.8 Mechanical properties of deformed samples aged at $500{ }^{\circ} \mathrm{C}$ for $8 \mathrm{~h}$ along rolling direction are mainly controlled by following factors. (1) The grain size, which depends on the degree of deformation, is an important parameter for strength and ductility of the alloy. The small grain size will increase the ultimate strength of the alloy according to the Hall-patch relationship ${ }^{[15,16]}$. It will make a great contribution to the ultimate strength because the newborn grain boundary will limit the maximum slip length in the tensile test process. (2) The dislocation, generated in deformation process will offer more nucleation sites for the transformation of $\beta$ to $\alpha$ phase. And the small size of $\alpha$ precipitates produced during aging heat treatment after severe cold deformation, can lead to a large number of $\alpha / \beta$ phase boundaries which act as effective dislocation barriers and have a very significant influence on properties. The trend of refining of $\alpha$ precipitates can explain why the strength is improved and the ductility is descended.

\section{Conclusions}

1) TB8 titanium with small strain will receive a plastic deformation mainly showing sub-grain formation induced plasticity. With the increase of degree of deformation, the way of the primary deformation will turn into dislocation slip.

2) TB8 alloy after cold deformation will have $\alpha$ transformation at dislocation sites or sub-grain boundaries in aging treatment process, and then the transformation of $\beta$ phase to $\alpha$ phase will occur with increasing of aging time.

3) Microstructures of TB8 alloy aged at $500{ }^{\circ} \mathrm{C}$ for $8 \mathrm{~h}$ are greatly impacted by the degree of cold deformation. Density of dislocation, grain distortion and residual $\beta$ phase generated in the cold deformation process will affect the precipitation of second $\alpha$ phase in aging treatment process. For the aged alloy, its strength is improved and ductility is descended with the increase of degree of cold-deformation.

\section{References}

1 Li Chenglin, Mi Xujun, Ye Wenjun et al. Journal of Alloys and Compounds[J], 2013, 550: 23

2 Du Zhaoxin, Xiao Shulong, Xu Lijuan et al. Materials and Design[J], 2014, 55: 183

3 Malinov S, Sha W, Guo Z et al. Materials Characterization[J], 2002, 48: 279

4 Min X H, Tsunami K, Emura S et al. Materials Science and Engineer $A[\mathrm{~J}], 2012$, 554: 53

5 Mantani Y, Tajima M. Materials Science and Engineer A[J], 2006, 438-440: 315

6 Sun F, Prima F, Gloriant T. Materials Science and Engineer A[J], 2010, 527: 4262

7 Wang Liqiang, Lu Weijie, Qin Jining et al. Materials Science and Engineer A[J], 2008, 490: 421

8 Kou Hongchao, Chen Yi, Tang Bin et al. Journal of Alloys and Compounds[J], 2014, 603: 23

9 Josephine Prabha A, Raju S, Jeyaganesh B et al. Physical B[J], 
2011, 406: 4200

10 Porter D A, Easterling K E. Phase Transformations in Metals and Alloys[M]. London: Chapman \& Hall, 1992: 415

11 Zhang Yuchao, Xing Zhigang, Ma Ziguang et al. Science in China Series g-Physics Astronomy[J], 2010, 53(3) : 465

12 Aeby-Gautiera E, Settefratia A, Bruneseauxa F et al. Journal of Alloys and Compounds[J], 2012, 577: 439

13 Ivasishin $\mathrm{O} \mathrm{M}$, Markovsky $\mathrm{P} \mathrm{E}$, Matviychuk $\mathrm{Yu} \mathrm{V}$ et al.
Metallurgy and Materials Transaction A[J], 2003, 34A: 147

14 Yoshito Takemoto, Ichiro Shimizu, Akira Sakakibara et al. Materials Transactions[J], 2004, 45(5): 1571

15 Yoshikazu Mantani, Yoshito Takemoto, Moritaka Hida et al. Materials Transactions[J], 2004, 45(5): 1629

16 Chen Yuyong, Du Zhaoxin, Xiao Shulong et al. Journal of Alloys and Compounds[J], 2014, 586: 588

\title{
TB8 钛合金冷变形过程的组织演变及其热处理时效响应
}

\author{
徐铁伟 ${ }^{1,2}$, 李金山 ${ }^{1}$, 张丰收 ${ }^{1,2}$, 王飞云 ${ }^{2}$, 刘向宏 ${ }^{1,2}$, 冯 勇 $^{1,2}$ \\ (1. 西北工业大学, 陕西 西安 710072) \\ (2. 西部超导材料科技股份有限公司，陕西 西安 710018)
}

\begin{abstract}
摘 要: 钛合金冷加工过程中组织演变行为取决于形变量, 而冷形变组织的差异深刻影响着热处理过程中的时效相变行为。利用场发射 扫描电镜 (FE-SEM), X 射线衍射 (XRD) 仪, 差热分析 (DSC) 仪, 硬度 (HV) 分析等测试手段和分析方法, 比较系统地研究了 TB8 钛合金在冷加工过程中的组织演变以及随后的热处理时效强化响应行为。结果表明：增高的 FWHM 是由于合金在冷变形中发生晶粒畸 变和产生位错引起的, 同时维氏硬度的增长也伴随着亚晶和畸变的增加。通过相变的研究说明冷变形对于 $\alpha$ 相析出相变行为的影响, 并 揭示了冷形变钛合金存在特殊的时效相变行为。
\end{abstract}

关键词: 相变; 冷变形; 钛合金; 时效响应

作者简介: 徐铁伟, 男, 1982 年生, 博士生, 西北工业大学材料学院, 陕西 西安 710072, 电话: 029-86527358, E-mail: twxu@ 163.com 